\title{
A new experimental approach to study the hygroscopic and optical properties of aerosols: application to ammonium sulfate particles
}

\author{
C. Denjean, P. Formenti, B. Picquet-Varrault, Y. Katrib, E. Pangui, P. Zapf, and J. F. Doussin \\ Laboratoire Interuniversitaire des Systèmes Atmosphériques (LISA), UMR7583 - CNRS, Université Paris-Est-Créteil \\ (UPEC) et Université Paris Diderot (UPC), Institut Pierre Simon Laplace (IPSL), Créteil, France
}

Correspondence to: C. Denjean (cyrielle.denjean@lisa.u-pec.fr)

Received: 10 June 2013 - Published in Atmos. Meas. Tech. Discuss.: 29 July 2013

Revised: 4 December 2013 - Accepted: 9 December 2013 - Published: 23 January 2014

\begin{abstract}
A new methodology for the determination of the changes due to hygroscopic growth with relative humidity of the number size distribution and optical properties of polydispersed aerosols is described. This method uses the simulation chamber CESAM where the hygroscopic properties of polydispersed aerosol particles can be investigated in situ by exposing them to RH ranging from 0 to $100 \%$ for approximately $1 \mathrm{~h}$. In situ humidification is used to provide simultaneous information on the RH-dependence of the particle size and the corresponding scattering coefficient $\left(\sigma_{\text {scat }}\right)$, and that for the entire size distribution. Optical closure studies, based on integrated nephelometer and aethalometer measurements, Mie scattering calculations and measured particle size distributions, can therefore be performed to yield derived parameters such as the complex refractive index (CRI) at $\lambda=525 \mathrm{~nm}$. The CRI can also be retrieved in the visible spectrum by combining differential mobility analyzer (DMA) and white light aerosol spectrometer (Palas Welas ${ }^{\mathrm{TM}}$ ) measurements.

We have applied this methodology to ammonium sulfate particles, which have well known optical and hygroscopic properties. The CRI obtained from the two methods (1.541.57) compared favourably to each other and are also in reasonable agreement with the literature values. The particle's growth was compared to values obtained for one selected size of particles $(150 \mathrm{~nm})$ with a H-TDMA and the effect of the residence time for particles humidification was investigated. When the humidification was performed in the chamber for a few minutes, a continuous increase of the ammonium sulfate particle's size and $\sigma_{\text {scat }}$ was observed from RH values as low as $30 \%$ RH. Comparison of the measured and modelled values based on Köhler and Mie theories shows that
\end{abstract}

layers of water are adsorbed on ammonium sulfate particles below the deliquescence point. In contradiction, the particle's growth reported with H-TDMAs showed a prompt deliquescence of ammonium sulfate particles with no continuous growth in size at low RH. These findings highlight the need to allow sufficient time for particle-water vapour equilibrium in investigating the aerosols hygroscopic properties. H-TDMA instruments induce limited residence time for humidification and seem to be insufficient for water adsorption on ammonium sulfate particles.

\section{Introduction}

Atmospheric aerosols play an important role in the Earth's climate by absorbing and scattering incoming solar radiation and outgoing terrestrial radiation (direct effect) (Haywood et al., 1998; Charlson et al., 1992; Forster et al., 2007), but also by altering cloud properties by acting as cloud condensation nuclei (CCN) and thereby modifying cloud albedo, lifetime and precipitation (indirect effect) (Hansen et al., 1997; Albrecht, 1989; Lohmann and Feichter, 2005).

The ability of aerosols to interact with radiation is determined by their optical properties (single scattering albedo, asymmetry factor and efficiency of light extinction), strong functions both of particle size and chemical composition. The chemical composition determines the complex refractive index (CRI) $(m=n+i k)$, which describes the scattering (real part $n$ ) and absorbing (imaginary part $k$ ) characteristics of a substance. The CRI is a major parameter to make the link between the instrinsic physic-chemical and the optical properties of aerosol particles. 
There are several means to determine the CRI of atmospheric aerosols. Nakayama et al. (2010) estimated the CRI in optical closure experiments based on measured particle size dependence of the extinction and scattering coefficients ( $\sigma_{\text {ext }}$ and $\left.\sigma_{\text {scat }}\right)$ together with Mie-Lorenz theory. This method uses instruments based on monochromatic radiation and thus allows the determination of CRI at specific wavelength. Due to a lack of data measured in the visible spectrum, another approach which combines measurements of aerosol size distributions with measurement techniques depending on different aerosol properties can also be used. Various authors (Flores et al., 2009; Wex et al., 2009; Sorooshian et al., 2008; Covert et al., 1990) installed a white light aerosol Optical Particle Counter (OPC) downstream a Differential Mobility Analyzer (DMA) to retrieve the particle's CRI. The OPC measures the particle optical size, which depends on the CRI, while the DMA measures a mobility diameter, that is, a geometric diameter when spherical particles are assumed. These instruments operate over different size ranges, but overlap does occur between them. The CRI can be determined based on the superposition, in the region of overlap, of the size distributions obtained from the DMA and those calculated from the OPC response to CRI.

The aerosol properties are strongly dependent on atmospheric conditions, in particular the relative humidity ( $\mathrm{RH})$ of ambient air. The interaction of particles with water is associated with changes in their size and their chemical composition, thereby modifying their potential to act as cloud condensation nuclei, their chemical reactivity, their scattering efficiencies and, in a lesser degree, their absorbing efficiencies (Orr Jr. et al., 1958; Hegg et al., 1993; Nemesure et al., 1995; Martin, 2000). Thus, laboratory quantification of the $\mathrm{RH}$ dependence of size and light scattering is necessary for inclusion into radiative transfer calculations (Charlson et al., 1992; Haywood and Ramaswamy, 1998; Hegg et al., 1993; Nemesure et al., 1995).

Most of previous laboratory studies have measured the change in particle diameter due to particle hygroscopic growth using Hygroscopic Tandem Differential Mobility Analyzers (H-TDMA). H-TDMAs were firstly introduced by Liu et al. (1978) and are used worldwide in laboratories (Meyer et al., 2009; Prenni et al., 2003; Saathoff et al., 2003; Varutbangkul et al., 2006) and during field campaigns (Saxena et al., 1995; Sjogren et al., 2007; Svenningsson et al., 1992). The parameter determined is the particle size growth factor (GF), i.e. the ratio of the particle diameter at a given $\mathrm{RH}$ to the particle diameter under low RH condition (Biskos et al., 2006; Swietlicki and Hansson, 2008; Prenni et al., 2003; Hämeri et al., 2000; Cruz and Pandis, 2000). This GF can be used to derive the number of $\mathrm{CCN}$ with Köhler theory for inorganic aerosols (Petters et al., 2009; Huff Hartz et al., 2005). A limitation of H-TDMA is that measurements of GF are usually performed for a single size class. However, Biskos et al. (2006) have shown that GF depends on particle size. For a fixed composition, particles smaller than $100 \mathrm{~nm}$ exhibit smaller GF than larger particles because of the larger relative contribution of the surface term to the free particle energy. To be relevant to climate modelling, it is therefore extremely important that the GF of the full size distribution of polydisperse aerosols is known.

In addition, model calculations on the direct radiative effect also require data on the influence of RH on $\sigma_{\text {scat }}$ (Charlson et al., 1992). Mie scattering theory has been used in the past to calculate the RH dependence of light scattering using GF of many inorganic compounds (Garland et al., 2007; Beaver et al., 2008; Wex et al., 2005). However, because of a lack of optical and thermodynamic data for many organic compounds, the change in $\sigma_{\text {scat }}$ due to water uptake is not fully predicted (Malm et al., 2005; Saxena et al., 1995). As a consequence, direct measurements of the $f(\mathrm{RH})$, i.e. the ratio of $\sigma_{\text {scat }}$ at high RH to the $\sigma_{\text {scat }}$ under low RH condition, have been monitored using RH-controlled nephelometers (Kus et al., 2004; Covert et al., 1972; Yoon and Kim, 2006; ten Brink et al., 2000).

This work describes a new experimental approach for the simultaneous measurement of hygroscopic growth of particle size distribution and optical properties of polydispersed aerosols. Our setup is based on the use of the largevolume simulation chamber CESAM (French acronym for Experimental Multiphasic Atmospheric Simulation Chamber) hosted at the Laboratoire Interuniversitaire des Systèmes Atmosphériques in Créteil, France. Atmospheric simulation chambers allow acquiring data on the physical-chemical, optical and hygroscopic properties of specific aerosols under controlled ambient conditions, and along the aerosol lifecycle, also simulating the evolution that particles would endure during transport due to oxidation and photolysis in the atmosphere (Meyer et al., 2009; Henry and Donahue, 2012; Tritscher et al., 2011). The CESAM chamber is most dedicated to studies of organic aerosols from oxidation of volatile organic compounds (VOCs) (Yasmeen et al., 2012), which are weakly hygroscopic and absorbing, but whose properties and effect on climate are largely unknown because dependent on the gaseous precursors and conditions of oxidations (Kanakidou et al., 2005).

This paper describes the experimental set up and approach developed for these studies, and applied to ammonium sulfate particles. Ammonium sulfate aerosols are a dominant component of the submicron aerosol mass in the atmosphere and an efficient scatterer of solar radiation (Charlson et al., 1992). This aerosol is well suited for the validation of our methodology as both the optical and hygroscopic properties of these particles were intensively studied in the past (Tang, 1996; Cruz and Pandis, 2000; Gysel et al., 2001; Dinar et al., 2008; Riziq et al., 2007; Flores et al., 2009). Regarding the aerosol optical properties, in this paper we have retrieved the CRI both at a specific wavelength in the midvisible, and integrated over the visible spectrum. The hygroscopic behaviour of aerosols has been investigated by measuring the RH dependence of size and $\sigma_{\text {scat }}$ of the overall size 
distribution up to $100 \%$ RH. Measured GFs have been compared to values obtained with a custom-built H-TDMA. The effect of the residence time for particles humidification has been investigated.

\section{Experimental methods}

\subsection{Atmospheric simulation chamber set-up}

The CESAM chamber is designed to allow research in multiphase atmospheric (photo)-chemistry which involves both gas phase and condensed phase processes including aerosol and cloud chemistry. The chamber is described in detail elsewhere (Wang et al., 2011), but characteristics relevant to this study are reported here. CESAM consists of a $4.2 \mathrm{~m}^{3}$ stainless steel chamber. Aerosols exhibit a lifetime long enough to study aerosol aging over several hours or days, depending on the aerosol size distribution. Typically, the particles lifetime for particles with a mass concentration of $100 \mu \mathrm{g} \mathrm{m}^{-3}$ and a number size distribution centred at $100 \mathrm{~nm}$ is about 2 days. In CESAM, it is possible to vary in situ the RH of the reaction mixture by adding water vapour in the reactor. Both temperature and RH are measured with a HMP234 Vaisala humidity and temperature transmitter equipped with a capacitive thinfilm sensor Humicap. The sensor was factory calibrated prior to the experiments and has an RH accuracy of $\pm 1.9 \%$ up to $90 \% \mathrm{RH}$ and a temperature accuracy of $\pm 0.1{ }^{\circ} \mathrm{C}$ at $20^{\circ} \mathrm{C}$.

Figure 1 shows a schematic of the experimental setup to measure aerosol properties.

\subsubsection{Size distributions}

A white light aerosol OPC (Welas, Palas, model 2000) was used to determine the number size distribution of particles with diameters above $300 \mathrm{~nm}$ by measuring the pulse of scattered white light. The white light spectrum is spanned from 370 to $780 \mathrm{~nm}$. The OPC was calibrated using a calibration dust standard (CalDust 1100) which has the same CRI as polystyrene latex (PSL). No RH sensor was installed in the sample inlet of the OPC. The OPC was only used under dry conditions.

A scanning mobility particle sizer (SMPS) that includes a differential mobility analyzer (DMA, TSI model 3080) interfaced to a condensation particle counter (CPC, TSI model 3010) was used to monitor sub-micrometer particle number size distribution. The DMA was operated at flow rates $3 / 0.3 \mathrm{Lpm}$ (sheath flow/aerosol sample flow). The aerosol sample flow was set by the CPC with a nominal flow rate of $0.3 \mathrm{Lpm}$. The resulting measured size distribution ranged between 14 to $505 \mathrm{~nm}$. For its RH control, capacitive RH sensors (Vaisala, model HMP-50) were placed in the aerosol sample, sheath, and excess air. The RH of the aerosol sample flow was controlled by the RH inside the chamber. The sheath flow was humidified at the same RH as the aerosol sample flow by passing through a multiple-tube Nafion

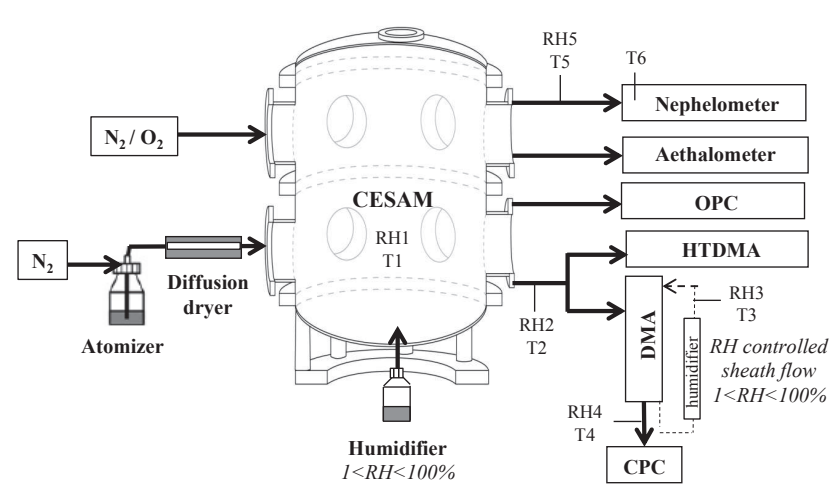

Fig. 1. Experimental set up used to measure aerosol hygroscopic and optical properties.

conditioner (Permapure, model PD-50T) to avoid RH gradients in the DMA. Hydrophilic filters in the sheath flow were replaced by hydrophobic ones to avoid water vapour release. The same set-up has been used for the DMA2 of the H-TDMA, as it will be described in details in Sect. 2.1.3. The size calibration of the SMPS was performed using monodisperse PSL particles (Duke Scientific) of diameters ranging from 100 to $500 \mathrm{~nm}$, which were produced with a constant output atomizer (TSI model 3075). The retrieved diameters were found to be larger than the PSL certified diameters (by about $10 \%$ for $100 \mathrm{~nm}$ PSL spheres). A correction factor was therefore applied.

\subsection{Optical properties}

The aerosol scattering coefficient was measured using an integrating nephelometer (model M9003, Ecotech). This instrument has a LED source that provides light at $525 \mathrm{~nm}$ wavelength. The light scattered by particles at scattering angles between $10^{\circ}$ and $170^{\circ}$ is collected with a photomultiplier (Liu et al., 2008). The nephelometer was calibrated with filtered air and $\mathrm{CO}_{2}$ separately. The sample air is usually drawn by a fan through the sample inlet into the measurement volume. Because our experiments were carried out at a pressure 3 mbar higher than the atmospheric pressure, the circulating air system of the nephelometer does not allow the flowrate control. Thus, the fan was replaced by an external pump working at $3 \mathrm{Lpm}$. The temperature was measured both at the sample inlet and within the cell of the nephelometer with an accuracy of $\pm 0.6^{\circ} \mathrm{C}$, and the $\mathrm{RH}$ was measured within the cell of the nephelometer with an accuracy of $\pm 3 \%$. $\sigma_{\text {scat }}$ was corrected for the sample temperature and pressure, as well as for angular truncation taking into account the nephelometer geometry, so to quantify the light scattering at scattering angles below $10^{\circ}$ and above $170^{\circ}$. For the particle number size distribution in this study, the mean correction factor for $\sigma_{\text {scat }}$ was within $6 \%$.

The aerosol light absorption coefficient was derived from the aerosol light attenuation measured with an aethalometer 
(Model AE31, Magee Scientific). The aethalometer measures the optical attenuation of light transmitted through the aerosols deposited continuously on a quartz fibre filter. It operates with several light sources at seven wavelengths covering the near ultra-violet to the near infrared wavelength range $(\lambda=370,470,520,590,660,880$ and $950 \mathrm{~nm})$. It has been observed that the aethalometer can suffer from biases at high $\mathrm{RH}$ as a result of filter taking up water and scattering more light compared to the reference measurement (Cappa et al., 2008; Arnott et al., 2005). Therefore, the aethalometer was not used during the humidification of aerosols.

\subsubsection{Development of a $\mathrm{H}$-TDMA}

In order to measure the water uptake of monodisperse particles, a H-TDMA composed of two DMAs in series, an aerosol humidifier in between, and a CPC at the exit has been developed. A diagram of the layout of the H-TDMA is shown in Fig. 2.

The dry aerosol passes through a diffusion charger $\left({ }^{85} \mathrm{Kr}\right)$ to reach a bipolar charge distribution and an initial mobility diameter is selected with a first DMA. The resulting monodisperse aerosol then passes through a humidifier at a well-defined RH, and a second DMA coupled to a CPC measures the wet size distribution over mobility diameter. In this study, both DMAs are TSI 3080 types operating at flow rates $3 / 0.3 \mathrm{Lpm}$ (sheath flow/aerosol sample flow). The flow rate of the CPC (TSI 3075) was set at $0.3 \mathrm{Lpm}$. A closedloop recirculation was used for the sheath flow in the DMA in order to facilitate the RH control. As for the SMPS setup, the sheath air hydrophilic filter was replaced by a hydrophobic filter (Whatman, model 6702-7500). This procedure avoids RH gradients inside the DMA, and reduces the risk of particle size changes. The two DMAs were calibrated using monodisperse PSL particles (Duke Scientific) ranging from 100 to $500 \mathrm{~nm}$. As described in Sect. 2.1.1., a size shift was observed for the two DMAs and thus a correction was applied for the retrieved diameters. DMAs were also intercalibrated before each H-TDMA measurement by sectioning different diameters with the first DMA and scanning the resulting size distribution with the second DMA (Fig. S1 in the Supplement). The retrieved diameters with the second DMA agreed with the selected diameters by the first DMA after size shift correction, therefore no more correction was applied to the DMAs diameters.

The RH of sheath and aerosol flows are adjusted independently to the desired value by passing through a multiple-tube Nafion conditioner (Permapure, model PD50T). Water saturated air is generated by bubbling highpurity water (18.2M $\Omega$, ELGA Maxima). The humidification for both the aerosol and the sheath flows is controlled by a proportional-integral-derivative (PID) controller programmed using LabVIEW ${ }^{\mathrm{TM}}$ which provides feedback to the $\mathrm{RH}$ sensors and thereby adjusts the bubbling rate. The sheath flow is humidified at the same RH as the aerosol sample

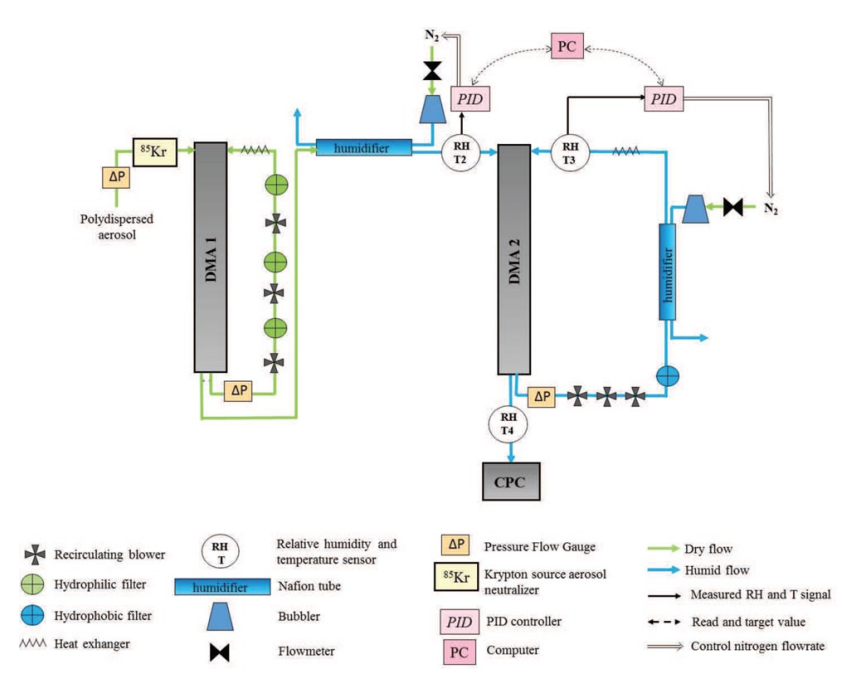

Fig. 2. Schematic diagram showing the layout of the H-TDMA.

flow to avoid RH gradients in the DMA2. The temperature can have significant influence on RH, especially at high RH. Our H-TDMA is not directly controlled in temperature yet. Therefore, a specific attention was given to prevent drafts and keep temperature of the room stable. In addition, a heat exchanger is located at the exit of the sheath flow to equilibrate the temperature due to the compressive blower heating. Tests were performed to evaluate the system ability to maintain a stable humidity. The RH set point was set at a constant value of $90 \%$ during $5 \mathrm{~h}$. In this way, the measured RH was within $\pm 2 \%$ of the target value.

No RH sensor was installed at the inlet of the first DMA, for which we used the measurement of RH in the chamber as a proxy. The RH within the chamber was always $<1 \%$ during the H-TDMA measurements. The RH of the DMA2 was monitored both at the inlet and outlet by three capacitive RH sensors (Vaisala, model HMP-50) placed in the aerosol sample, sheath, and excess air flows. The sensors have an accuracy of $\pm 3 \%$ up to $90 \% \mathrm{RH}$. They also measure the temperature with an accuracy of $\pm 0.6^{\circ} \mathrm{C}$ at $20^{\circ} \mathrm{C}$.

The H-TDMA/SMPS and nephelometer T/RH sensors were calibrated by collocating them in the CESAM chamber where the RH was varied from 0 to $100 \%$ and by using the CESAM sensor as the reference. The intercomparison of the temperature sensors shows a good agreement within uncertainties. However, the instruments sensors were found to be lower than the CESAM sensor in RH by 10 to $20 \%$ and thus a correction was applied.

The residence time of particles for humidification is equal to the residence time in the RH conditioner $(10 \mathrm{~s})$ plus the transit time in the second DMA $(5 \mathrm{~s})$. This is generally sufficiently long for particles to reach their equilibrium with water vapour (Chan and Chan, 2005; Saxena et al., 1995; Duplissy et al., 2009). 


\subsection{Experimental procedure}

Before each experiment, the chamber was cleaned by pumping at a secondary vacuum $\left(4.10^{-4} \mathrm{mbar}\right)$ overnight. The chamber was filled with a synthetic air produced from the mixture of 200 mbar of oxygen (Air Liquide, Alphagaz class 1, purity $99.9 \%$ ) and 800 mbar of nitrogen produced from the evaporation of a pressurized liquid nitrogen tank. The background aerosol concentration was below $0.1 \mu \mathrm{g} \mathrm{m}^{-3}$. Particles were generated from $0.03 \mathrm{M}$ ammonium sulfate solution using a constant output atomizer (TSI, model 3075), then they were passed through a diffusion dryer (TSI, model 3062) which reduced the $\mathrm{RH}$, before being introduced to the chamber. At the injection, the RH in the chamber was much lower than $1 \%$ which further dried out the particles. The RH in the chamber was measured throughout the whole experiment with RH sensor inside the chamber and was always smaller than $1 \% \mathrm{RH}$ before the humification. Between the end of the injection and the start of water vapour injection, the particles were allowed to reside in the chamber for several minutes. Ammonium sulfate particles were dried at $\mathrm{RH}$ lower than their deliquescence point and existed as crystalline phases. The initial starting conditions of all conducted experiments are summarized in Table 1.

The size, the optical properties and the water uptake of monodisperse aerosols (as measured with the H-TDMA) were monitored under dry conditions after the mass of ammonium sulfate particles reached its maximum value in the chamber. At the end of the experiments, the hygroscopicity of polydisperse particles were investigated by injecting water vapour produced in a small glass vessel filled with ultrapure water $(18.2 \mathrm{M} \Omega$, ELGA Maxima) which is located below the chamber and directly connected to it. The RH in the chamber increased linearly from 0 to $100 \%$ in approximately $1 \mathrm{~h}$. In order to avoid any RH inhomogeneities within the chamber, great care has been taken to inject the water vapour slowly and continuously. A stainless steel fan was installed inside the chamber to mix the reacting mixture with water vapour throughout the whole chamber volume. Tests were performed to evaluate the homogeneity of the RH throughout the chamber: water vapour was introduced step-by-step in the chamber in order to obtain various level of constant RH. The RH was measured at different points of the chamber with various sensors. It was observed that the sensors were in agreement with one another and the homogeneity of the $\mathrm{RH}$ was obtained in less than $1 \mathrm{~min}$.

The SMPS and the nephelometer were used to follow in situ the variation in number size distribution and $\sigma_{\text {scatt }}$ as a function of RH. As previously discussed, the RH of aerosols was controlled by the RH inside the chamber and monitored by two capacitive RH sensors placed at the inlet of both the SMPS and the nephelometer. The sheath flow of the SMPS was humidified at the same RH as the aerosol sample flow to avoid RH gradients in the DMA by passing through a multiple-tube Nafion conditioner and monitored with another capacitive RH sensor placed in the circuit of the sheath flow.

\section{Data analysis}

\subsection{Determination of the complex refractive index}

The complex refractive index (CRI) of ammonium sulfate particles was obtained by different methods. The CRI was only retrieved under dry conditions, when the RH was $<1 \%$ in the simulation chamber as well as the entrance of both the nephelometer and the SMPS. As particles were lost by dilution during the experiment, a correction of the number concentration, $\sigma_{\text {scat }}$ and $\sigma_{\text {abs }}$ was applied by using the instrument flowrate and assuming a first order correction.

\subsubsection{Complex refractive index at a specific wavelength}

The ammonium sulfate CRI at $525 \mathrm{~nm}$ was firstly derived by optical closure experiments involving measured $\sigma_{\text {scat }}$ and $\sigma_{\mathrm{abs}}$ and the number size distribution also determined experimentally. At a fixed wavelength $\lambda, \sigma_{\text {scat }}$ and $\sigma_{\text {abs }}$ can be calculated according to the following equation:

$$
\begin{aligned}
& \sigma_{\text {scat }, \text { abs }}(\lambda, m)= \\
& \sum_{D_{\mathrm{p}}} Q_{\text {scat, abs }}\left(D_{\mathrm{p}}, \lambda, m\right) \frac{\pi}{4} D_{\mathrm{p}}^{2}\left(\frac{\mathrm{d} N}{\mathrm{~d} \log D_{\mathrm{p}}}\right) \mathrm{d} \log D_{\mathrm{p}}
\end{aligned}
$$

where $D_{\mathrm{p}}$ is the geometrical particle diameter, $\frac{\mathrm{d} N}{\mathrm{~d} \log D_{\mathrm{p}}}$ the number size distribution and $Q_{\text {scat,abs }}\left(D_{\mathrm{p}}, \lambda, m\right)$ the scattering and absorption efficiencies of a single particle of CRI equal to $m$.

The optimal CRI was determined so that the difference between measured $\sigma_{\text {scat }}$ and $\sigma_{\text {abs }}$ and those obtained using Mie calculations was minimized.

For homogeneous spheres, $Q_{\text {scat, abs }}\left(D_{\mathrm{p}}, \lambda, m\right)$ can be calculated using Mie scattering described by Bohren and Huff$\operatorname{man}(1983)$.

Since ammonium sulfate is composed by spherical particles (Pruppacher and Klett, 1996), the electrical mobility diameter is identical to geometrical diameter. Therefore, the mobility diameters measured by SMPS was directly used for the calculations. Number size distributions obtained with the SMPS were fitted with log-normal size distributions:

$$
\frac{\mathrm{d} N}{\mathrm{~d} \log D_{\mathrm{p}}}=\frac{N_{\mathrm{tot}}}{\sqrt{2 \pi} \log \sigma} \exp \left[-\frac{\left(\log D_{\mathrm{p}}-\log D_{\mathrm{p}, \mathrm{g}}\right)^{2}}{2(\log \sigma)^{2}}\right]
$$

where $N_{\text {tot }}$ is the integrated number concentration, $\sigma$ is the standard deviation and $D_{\mathrm{p}, \mathrm{g}}$ is the fitted geometric diameter.

The attenuation coefficient $\sigma_{\text {ATTN }}$ resulting from the attenuation of the sampled aerosols onto the filter was obtained as

$\sigma_{\mathrm{ATTN}}(\lambda, m)=\frac{A}{Q} \frac{\Delta \mathrm{ATN}}{\Delta t}$ 
Table 1. Summary of the experimental conditions for each experiment: Temperature, pressure, relative humidity in the chamber and the particles mass concentration injected in the chamber.

\begin{tabular}{|c|c|c|c|c|}
\hline Experiment number & Temperature (K) & Pressure (mbar) & Relative Humidity (\%) & [particles] $\max \left(\mu \mathrm{g} \mathrm{m}^{-3}\right)$ \\
\hline E2904 & 298 & 1001 & $<1$ & 180 \\
\hline E3004 & 296 & 1005 & $<1$ & 140 \\
\hline E0305 & 293 & 1002 & $<1$ & 143 \\
\hline E2809 & 291 & 1010 & $<1$ & 266 \\
\hline E1212 & 294 & 1001 & $<1$ & 110 \\
\hline
\end{tabular}

where $A$ is the spot area of the deposit, $Q$ the volumetric flowrate and $\triangle \mathrm{ATN}$ the change in attenuation during the time interval $\Delta t$. It is well known that $\sigma_{\text {ATTN }}$ obtained with the aethalometer is higher than the true $\sigma_{\text {abs }}$ (Bond et al., 1999; Weingartner et al., 2003; Arnott et al., 2005; Bond and Bergstrom, 2006; Cappa et al., 2008; Collaud Coen et al., 2010). Various systematic errors are induced by the aethalometer measurements that need to be corrected. Collaud Coen et al. (2010) proposed an empirical correction that includes $R$ the attenuation effect due to light absorbing particles accumulating in the filter, $C_{\text {ref }}$ the multiple scattering by the filter fibres and $\alpha(\lambda)$ the scattering correction due to scattering of aerosols embedded in the filter:

$\sigma_{\text {abs }}(\lambda, m)=\frac{\sigma_{\mathrm{ATTN}}(\lambda, m)-\alpha(\lambda) \cdot \sigma_{\text {scatt }}(\lambda, m)}{C_{\text {ref }} \cdot R}$

$R$ decreases with the gradual increase of attenuation due to the accumulation of absorbing particles embedded in the filter. Ammonium sulfate particles are known to be purely scattering particles (Tang, 1996; Riziq et al., 2007; Flores et al., 2009). Thus, we assumed that $R$ was equal to the unity.

$C_{\text {ref }}$ can be generally estimated by comparing $\sigma_{\text {ATTN }}$ measured with the aethalometer measurements and $\sigma_{\text {abs }}$ obtained from a non-filter based instrument (for example a photoacoustique photometer). However, simultaneous measurements with these two instruments were not possible during these experiments. Weingartner et al. (2003) measured the extinction coefficient $\sigma_{\text {ext }}$ and $\sigma_{\text {scat }}$ of pure ammonium sulfate particles. The authors showed no significant absorption and thus $C_{\text {ref }}$ could not be deduced from these measurements. Therefore, we used $C_{\text {ref }}=1.9$, the value which is often applied to aethalometer (Boudhaine, 1995; Petzold et al., 1997).

$\alpha(\lambda)$ was determined at the 7-wavelengths of the aethalometer according the method described by Arnott et al. (2005) as:

$\alpha(\lambda)=a^{d-1} c \lambda^{-b(d-1)}$

The constants $a, b, c$ and $d$ in Eq. (5) have been obtained experimentally. First, $\sigma_{\text {scat }}$ values at the aethalometer wavelengths have been calculated using Mie theory and by assuming that the CRI is spectrally neutral and equal to the value of $1.55+0 i$ obtained at $525 \mathrm{~nm}$ (Sect. 4.1). The power-law fit of $\sigma_{\text {scat }}$ provides with the Angström coefficient $b$ as

$\sigma_{\text {scat }}(\lambda)=a \lambda^{-b}$

We obtained $a=2.2( \pm 1.5) \times 10^{7}$ and $b=1.6( \pm 0.1)$.

For purely scattering particles, as ammonium sulfate, the attenuation measured with the aethalometer is due only to the effect of aerosol light scattering. In this case, a power law relationship links $\sigma_{\mathrm{ATTN}}$ to the values of $\sigma_{\text {scat }}$ as

$\sigma_{\mathrm{ATTN}}(\lambda)=c \sigma_{\text {scat }}(\lambda)^{d}$

We obtained $c=4.0( \pm 1.6) \times 10^{1}$ and $d=6.5( \pm 0.6) \times 10^{-1}$

Finally, $\alpha(\lambda)$ was retrieved by combining Eqs. (5), (6) and (7) as

$\alpha(\lambda)=1.3 \times 10^{-3} \lambda^{5.6 \times 10^{-1}}$

\subsubsection{Complex refractive index integrated over the visible spectrum}

The CRI in the visible was derived by comparing mobility size distributions obtained by the SMPS and optical size distributions measured simultaneously by the white-light OPC. The optical size distributions were corrected for various CRI according to the manufacturer calibration curves. The CRI was determined so that the optical size distributions match with those retrieved from SMPS measurements (Heim et al., 2008; Hand and Kreidenweis, 2002). While the Welas instrument is considered to provide size distribution down to $150 \mathrm{~nm}$, considering the decreased efficiency below $300 \mathrm{~nm}$, this last value was adopted as the lower border of the studied range. By identifying the best calibration curves, the CRI in the visible range was obtained for aerosol size range from 300 to $500 \mathrm{~nm}$. The uncertainties in retrieved CRI were determined from the difference between the DMA and OPC size distributions.

\subsection{Determination of the size and scattering growth factor}

The GF of monodisperse and polydisperse size distributions were derived from the H-TDMA and SMPS measurements, respectively. The GF represents the relative increase of the particle geometric diameter due to water uptake at a specific 
$\mathrm{RH}$ with respect to the geometric mobility diameter that this will have at a reference (low) value of the relative humidity as

$\mathrm{GF}(\mathrm{RH})=\frac{D_{\mathrm{p}, \mathrm{m}}(\mathrm{RH})}{D_{\mathrm{p}, \mathrm{m}}(\text { dry })}$,

where $D_{\mathrm{p}, \mathrm{m}}(\mathrm{RH})$ is the mobile geometric diameter at a specific RH and $D_{\mathrm{p}, \mathrm{m}}$ (dry) is the mobile geometric diameter at low RH considered correspond to dry conditions ( $\mathrm{RH}<30 \%$ ). Mobile diameters were calculated by assuming a lognormal profile as described in Sect. 3.1.1. Uncertainties in GF were based on the uncertainties in particle size distributions that included DMA classification and calibration, as well as uncertainties in the estimation of $D_{\mathrm{p}, \mathrm{m}}$ from size distributions. The measured GF were compared with theoretical calculations according to the model of Biskos et al. (2006) based on the Köhler equations. The humidification in the chamber was performed on the polydisperse size distributions that include a fraction of particles smaller than $100 \mathrm{~nm}$ (Fig. 3). Due to the Kelvin effect, the water activity and hence the GF vary with size for particle size above $100 \mathrm{~nm}$. Thus, a correction for the Kelvin effect was included in the theoretical calculation for the comparison with the SMPS measurements (Biskos et al., 2006).

Additionally, changes of the aerosol scattering properties due to hygroscopic growth were followed with the nephelometer and are represented by the ratio of the scattering coefficient at a specific $\mathrm{RH} \sigma_{\text {scat }}(\mathrm{RH})$ to the dry scattering coefficient $\sigma_{\text {scat }}$ (dry):

$f(\mathrm{RH})=\frac{\sigma_{\text {scat }}(\mathrm{RH})}{\sigma_{\text {scat }}(\mathrm{dry})}$

An increase of $2{ }^{\circ} \mathrm{C}$ has been observed in the cell of the nephelometer in comparison to the sample inlet due to heating by the lamp. This effect can cause a reduction of the sample RH and thus an underestimation of $f(\mathrm{RH})$ (Kus et al., 2004; Dougle et al., 1998; ten Brink et al., 2000). A correction for the sample RH was applied using the measured sample inlet RH sensor and the measured sample temperature within the cell. The dependence of the saturation vapour pressure of water on temperature is given by the empirical expression (Hinds, 1999):

$P_{\mathrm{S}}(T)=\exp \left[16.7-\frac{4060}{(T-37)}\right]$,

where $T$ is the temperature and $P_{\mathrm{S}}$ the saturated vapour pressure. Assuming a constant amount of water vapour, the RH changes of the sample due to increasing temperature in the cell of the nephelometer can be calculated as follows:

$\frac{\mathrm{dRH}}{\mathrm{d} T}=\frac{-4060 \mathrm{RH}}{(T-37)^{2}}$.

The $f(\mathrm{RH})$ uncertainties were based on the scattering coefficient uncertainties and both the temperature and RH correction uncertainties.

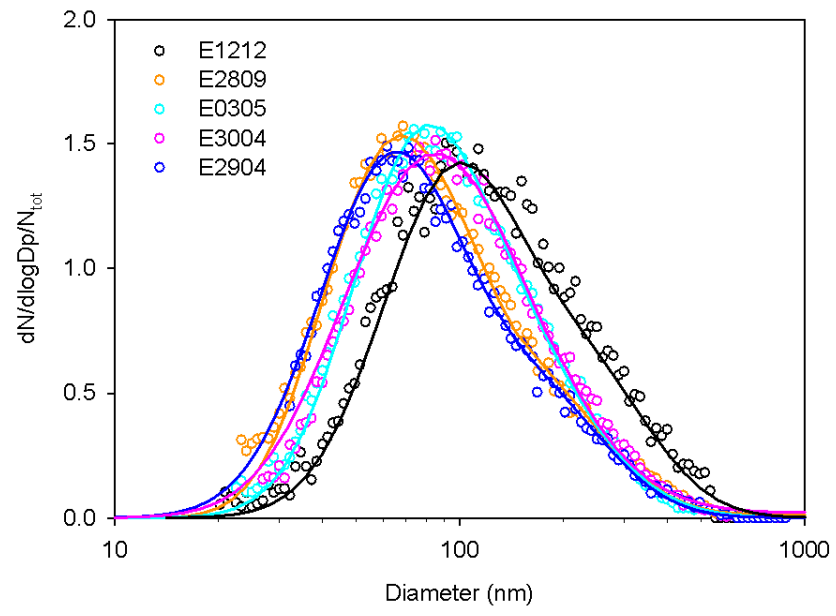

Fig. 3. Dry size distributions concentration for ammonium sulfate particles normalized by total number concentration $\left(N_{\text {tot }}\right)$ in the smog chamber before the injection of water vapour.

\section{Results}

\subsection{Refractive index of dry ammonium sulfate particles}

Figure 4 shows the attenuation and absorption coefficients at the 7-wavelength of the aethalometer. As expected, absorption by ammonium sulfate particles was zero within the error bars. As a consequence, the retrieval procedure was conducted by fixing the imaginary part of the CRI equal to zero.

Figure 5 compares values of $\sigma_{\text {scat }}$ at $\lambda=525 \mathrm{~nm}$ measured by the nephelometer to those calculated from the measured size distributions and Mie scattering theory for various CRI. The value of real part of the CRI allowing minimizing the difference between measurements and calculations within the estimated uncertainties was determined to be $1.55( \pm 0.02)$. The uncertainties were estimated from the difference between calculated $\sigma_{\text {scat }}$ and the uncertainties of $\sigma_{\text {scat }}$ measurements.

The real part of the CRI in the visible was retrieved by overlapping the number size distributions measured by the SMPS and the Welas-OPC. Figure 6 shows the optical size distributions corrected for various CRI and the corresponding mobility size distributions. For particles larger than $350 \mathrm{~nm}$, the SMPS spectrum was found to agree well with the white light spectrum by using a CRI of $1.54+0 i$. However, there is no clear evidence of the optimal CRI that would provide the best fit for particles smaller than $350 \mathrm{~nm}$ : the SMPS spectrum was found to agree with the white light spectrum by using a CRI between $1.54+0 i$ and $1.60+0 i$. As a result, the retrieved $\mathrm{RI}$ is $1.57( \pm 0.03)+0 i$.

The CRI values obtained in this study along with values reported in the literature are shown in Table 2. The CRI values obtained with the two methods are consistent with each other within the estimated uncertainties. At $\lambda=525 \mathrm{~nm}$, they are also in reasonable agreement with the literature values of 
Table 2. Retrieved RI of dry ammonium sulfate particles for $\lambda=$ $525 \mathrm{~nm}$ and in the visible.

\begin{tabular}{lll}
\hline Experiment number & $\lambda=525 \mathrm{~nm}$ & visible \\
\hline E2904 & $1.55( \pm 0.02)+0 i$ & $1.57( \pm 0.03)+0 i$ \\
E3004 & $1.54( \pm 0.02)+0 i$ & $1.57( \pm 0.03)+0 i$ \\
E0305 & $1.54( \pm 0.02)+0 i$ & $1.57( \pm 0.03)+0 i$ \\
E2809 & $1.55( \pm 0.02)+0 i$ & $1.57( \pm 0.03)+0 i$ \\
E1212 & $1.55( \pm 0.02)+0 i$ & $1.57( \pm 0.03)+0 i$ \\
Literature & $1.52+0 i^{\mathrm{a}}$ & \\
& $1.52( \pm 0.03)+0 i^{\mathrm{b}}$ & $1.52( \pm 0.01)+0 i^{\mathrm{d}}$ \\
& $1.52-1.54+0 i^{\mathrm{c}}$ & \\
\hline
\end{tabular}

Values taken from ${ }^{\text {a }}$ Riziq et al. (2007), ${ }^{\mathrm{b}}$ Nakayama et al. (2010), ${ }^{\mathrm{c}}$ Toon et al. (1976) and ${ }^{\mathrm{d}}$ Flores et al. (2009).

1.52+0i (Riziq et al., 2007), 1.52( \pm 0.03$)+0 i$ (Nakayama et al., 2010) and 1.52-1.54+0i (Toon et al., 1976). The CRI in the visible is slightly higher than the value of $1.52( \pm 0.01)+$ $0 i$ obtained by Flores et al. (2009). This difference may be due to the limited CRI available in the OPC correction protocol that reduces the accuracy of the retrieved CRI. However, the difference remains very low $(<3 \%)$ and closely linked to the value obtained at $\lambda=525 \mathrm{~nm}$.

\subsection{Hygroscopic growth of monodispersed particles measured with the H-TDMA}

The humidogram of ammonium sulfate injected in the CESAM chamber was measured by the H-TDMA for a selected dry size of $150 \mathrm{~nm}$ for RH between 45 and $90 \%$. In Fig. 7, our results are compared with theoretical calculations according to the model of Biskos et al. (2006) and with humidograms presented in the H-TDMA comparison study by Duplissy et al. (2009). The horizontal error bars describe the RH uncertainty in the second DMA. The vertical error bars show the GF uncertainty caused by the uncertainty in retrieving the geometric mobile diameters. The uncertainty of the GF due to the uncertainty in RH is not shown here, but we obtained $\mathrm{GF}=1.73 \pm 0.24$ at $90 \% \mathrm{RH}$ by using the theoretical calculations, that is $13 \%$ relative uncertainties.

At $\mathrm{RH}<78 \%$, dry particles exist as crystalline phase and no change in size was observed. The deliquescence transition was observed at $78.9 \pm 4.3 \%$, in agreement with data from Duplissy et al. (2009). Above this RH value, the size of ammonium sulfate particles increased sharply and a solution droplet was formed. In aqueous solution, particles grew by absorbing water vapour with increasing $\mathrm{RH}$ to maintain equilibrium with the water vapour. Again, the experimental growth factors agree well with the liquid phase theory and with other studies (Duplissy et al., 2009). The results show also the high precision of the H-TDMA in detecting small changes in GF when increasing RH by small increments $(<0.5 \% \mathrm{RH})$. Our instrument provides accurate measurements of particle hygroscopic growth and deliquescence.

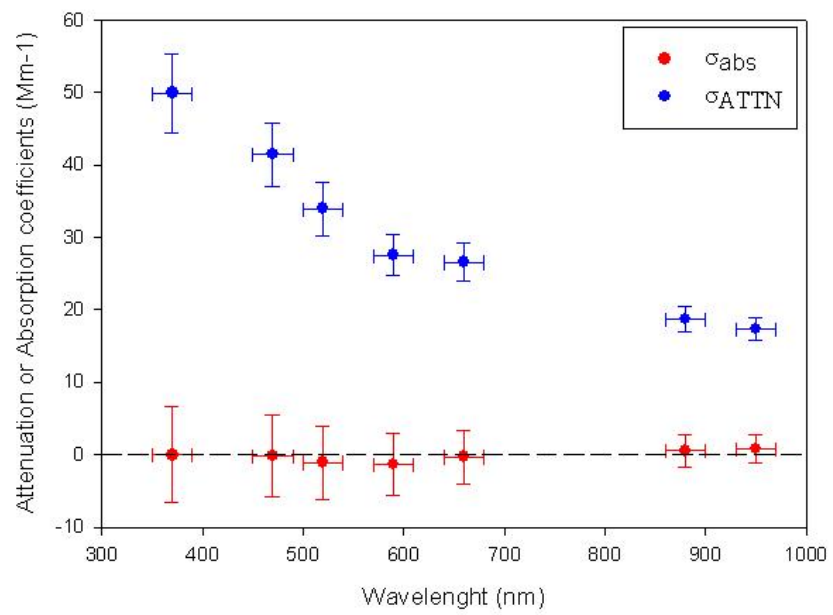

Fig. 4. Wavelength dependence of measured attenuation $\left(\sigma_{\text {ATTN }}\right)$ and the retrieved absorption $\left(\sigma_{\mathrm{abs}}\right)$ coefficients.

\subsection{Hygroscopic growth of polydisperse particles obtained by in situ humidification in the chamber}

The hygroscopic growth of polydisperse ammonium sulfate particles was obtained in situ by exposing particles to varying RH. Number size distributions as a function of $\mathrm{RH}$ are shown in Fig. 8. Two RH scales are used: within the smog chamber as well as the RH within the SMPS. Indeed, a decrease of RH was observed between the simulation chamber and both the nephelometer and the SMPS. The maximum decrease in the sample RH of $20 \%$ was observed in the SMPS and occurred for a RH of $100 \%$ in the chamber. A small drying of $10 \%$ was observed between CESAM and the cell of the nephelometer. The drying may be due to water transfer into the sample line as a result of the length of sample line's (about $1 \mathrm{~m}$ ) between CESAM and the instruments. Figure 8 shows that, for hydration up to $30 \% \mathrm{RH}$, the geometric diameter of particles did not change. From $30 \%$ RH, the particle's geometric diameter increased from $121 \mathrm{~nm}$ to $145 \mathrm{~nm}$ at $73 \%$ $\mathrm{RH}$, resulting in a GF of 1.2.

This hygroscopic behaviour was also observed for $\sigma_{\text {scat }}$ (Fig. 9). Above $30 \% \mathrm{RH}, \sigma_{\text {scat }}$ increased with RH suggesting possible changes in the chemical properties and/or in the size distribution of ammonium sulphate particles. A change in the slope was observed at $76 \% \mathrm{RH}$ that could be attributed to the deliquescence. Although the various curves exhibited the same trend, different values were observed for a specific RH. This can be explained by the fact that the size distribution of the aerosol in the chamber was slightly different from one experiment to another. In particular, the proportion of particles larger than $100 \mathrm{~nm}$ was different resulting in changing capacity in absorbing water (Biskos et al., 2006) and hence varying the observed GF and $f(\mathrm{RH})$. For example, $f(\mathrm{RH})$ in experiment E2904 was 1.6 for a dry geometric diameter 


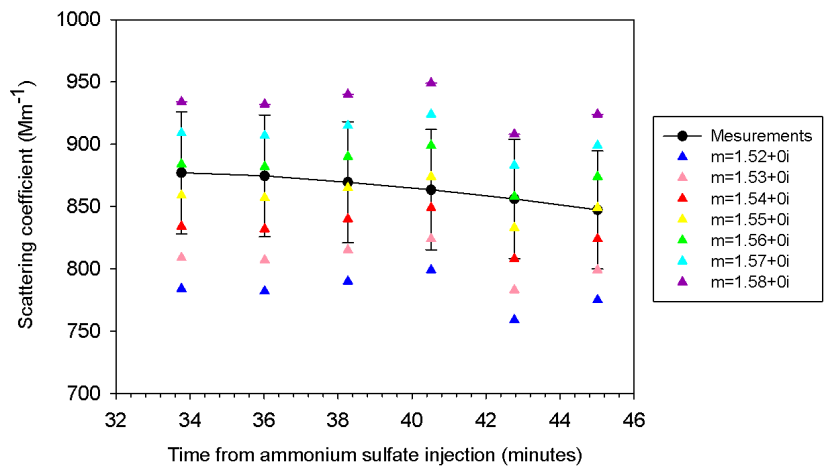

Fig. 5. Measured and calculated scattering coefficient using Mie scattering calculations for different CRI.

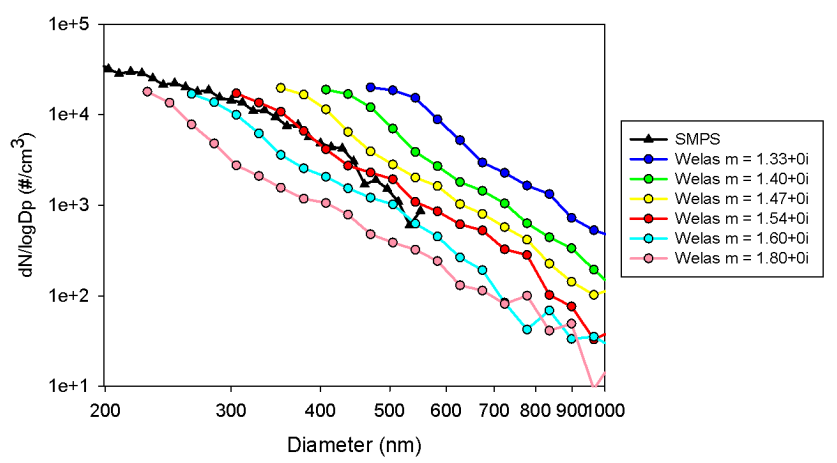

Fig. 6. Mobility size distribution (dark circles) and optical size distributions obtained for different CRI (coloured circles).

of $70 \mathrm{~nm}$ compared to 2.2 for $100 \mathrm{~nm}$ geometric diameter in experiment E1212

To rationalize these observations, the hygroscopic behaviour of particles measured using both the humidified SMPS and nephelometer during the chamber humidification were compared through a modelling study. We have considered that particles would exhibit different mixing states before and after their deliquescence RH. Figure 10 shows the methodology we applied to predict GF and $f(\mathrm{RH})$ as a function of RH.

After deliquescence, particles were considered to be transformed into an aqueous solution and the GF calculations were similar to those described in Sect. 3.2, based on Köhler equations. Dry particles and droplets were assumed to be homogeneous spheres of uniform CRI. The CRI calculations were based on volume weighted refractive indices of ammonium sulfate and water:

$\begin{aligned} n_{\text {aerosol }} & =n_{\text {ammonium sulfate }} x_{\text {ammonium sulfate }} \\ & +n_{\text {water }} x_{\text {water }}\end{aligned}$

where $x_{\text {ammonium sulfate }}$ and $x_{\text {water }}$ are respectively the volume fraction of ammonium sulfate and water. Mie scattering calculations for homogeneous spheres were used to determine the dry and humidified $\sigma_{\text {scat }}$ for $\lambda=525 \mathrm{~nm}$ both from

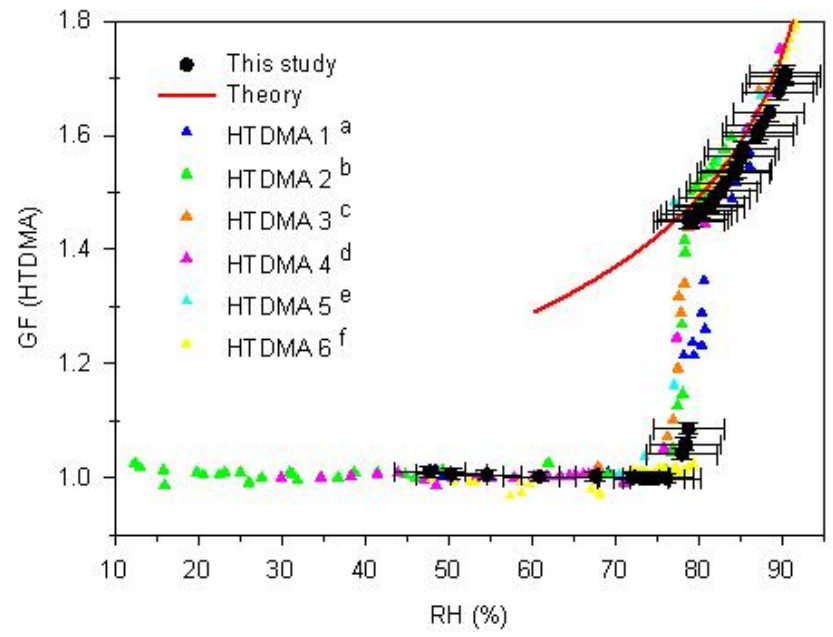

Fig. 7. Humidogram of $150 \mathrm{~nm}$ ammonium sulfate particles showing the hygroscopic growth factor measured with the H-TDMA as a function of relative humidity (black circle). The solid red line described the theory from Biskos et al. (2006). Humidograms from Duplissy et al. (2009) were added for comparison (coloured triangle).

measured GF at a specific RH and CRI. The ratio of the humidified $\sigma_{\text {scat }}$ to the dry $\sigma_{\text {scat }}$ gave the theoretical $f(\mathrm{RH})$.

To explain the hygroscopic behaviour before deliquescence, we made the assumption that ammonium sulfate particles may take up water in a shell-like structure. The scattering properties of this simple model can be described by the homogeneous coated sphere theory presented in Bohren and Huffman (1983). We assumed that particles were composed of a core that has the same CRI as ammonium sulfate and a water mantle. For the complex CRI of pure ammonium sulfate, we used the value retrieved in Sect. 4.1 at $\lambda=525 \mathrm{~nm}$. We made the assumption that the ammonium sulfate core size distribution did not change with RH. Therefore, changes of size distributions resulted from the change of the water mantle thickness coating ammonium sulfate particles. Hence, changes of $\sigma_{\text {scat }}$ were calculated from the observed thickness of the water mantle. We have also considered a model in which $\sigma_{\text {scat }}$ together with the optical code were used to derive the thickness of the water mantle and thus the GF as a function of the RH.

The hygroscopic behaviour of ammonium sulfate particles compared with model predictions is shown in Fig. 11. GF measurements agreed well with the model for RH above $76.2 \%$, suggesting that a solution droplet is formed. The deliquescence of ammonium sulfate particles was found to occur at a RH equal to $76.2 \pm 4.3 \%$, in agreement with results obtained with the H-TDMA (Sect. 4.2). Before the deliquescence point, GF curves were in agreement within measurement uncertainties considering the core-shell model, while the particle's growth cannot be attributed to any of the deliquescence or efflorescence curve and whatever the $\mathrm{RH}$ 

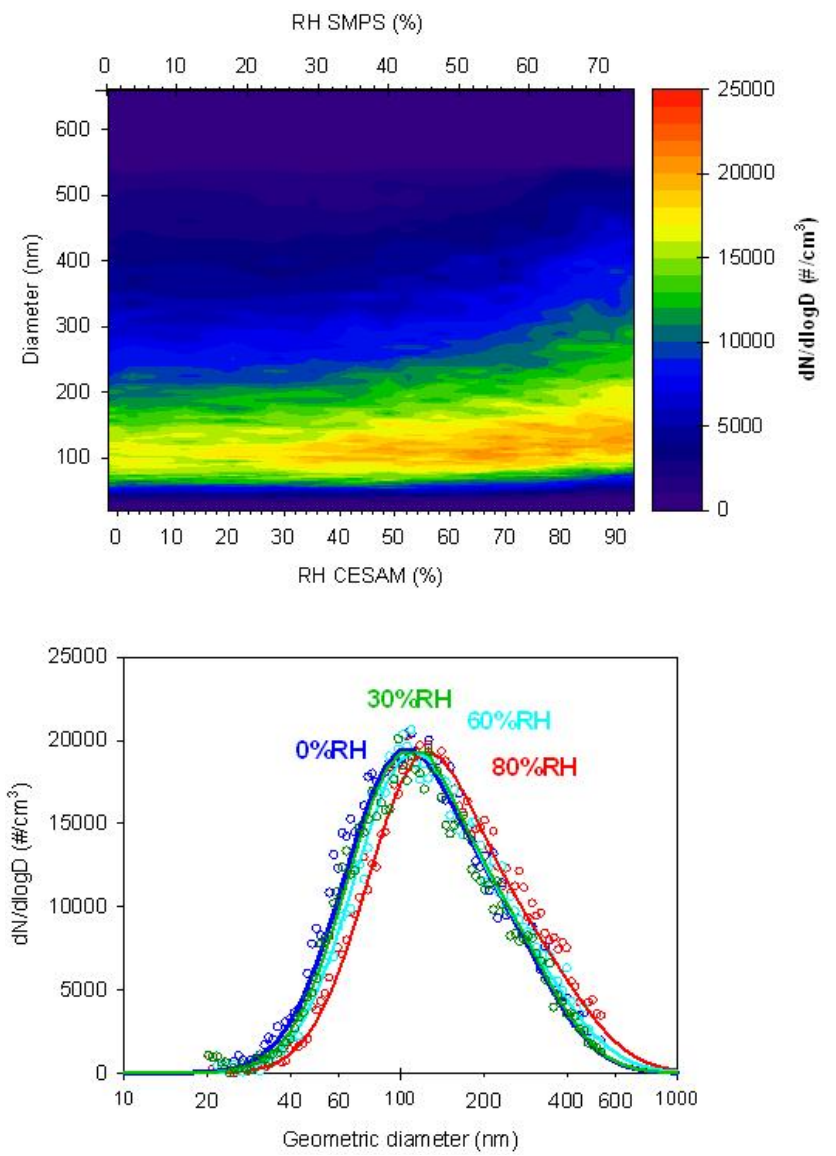

Fig. 8. Number size distribution of ammonium sulfate particles for increasing RH during humidification in the chamber in the experiment E1212.

considered (Fig. 12). Due to the drying out of the sample between CESAM and the instruments, the comparison between $f(\mathrm{RH})$ measurements and the model assuming particle deliquescence was possible only for $\mathrm{RH}=73.3 \%$, whereas only for RH below $58.3 \%$ we could compare results by considering a model where ammonium sulfate particles are surrounded by a shell of condensed water. After the deliquescence, $f(\mathrm{RH})$ agreed with the model for $\mathrm{RH}=73.3 \%$, but RH below $58.3 \%$ values were too low to allow a conclusive comparison between the measurement and the theoretical curve (Fig. 11b).

\section{Discussion}

Our results obtained by in situ humidification of polydispersed particles in the CESAM chamber suggest that ammonium sulfate particles absorb water far before deliquescence. This continuous absorption of water was not observed with our H-TDMA, as well as in several previous studies using this instrument (Duplissy et al., 2009; Gysel et al., 2001). There are three main differences between the H-TDMA and

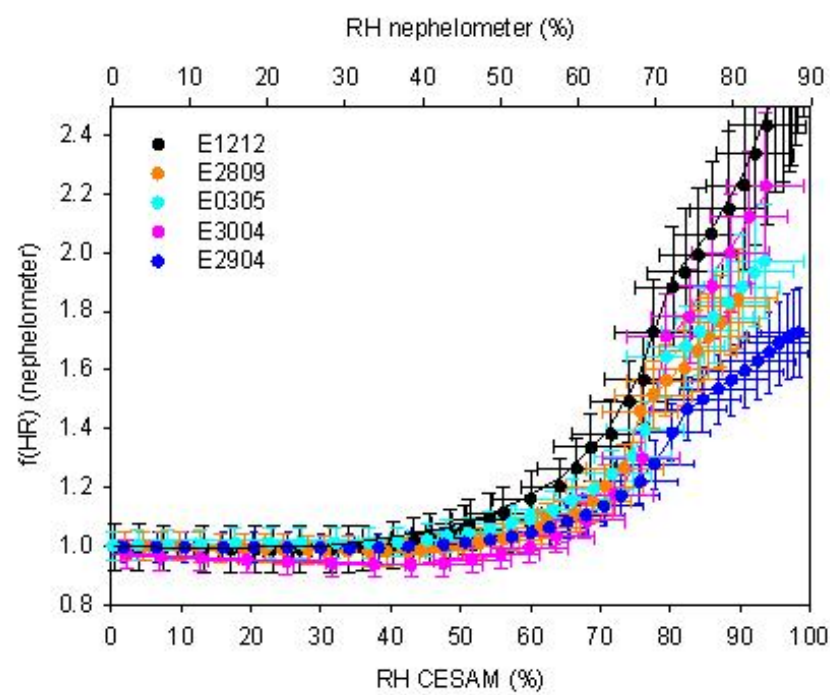

Fig. 9. Scattering growth factor $f(\mathrm{RH})$ as a function of $\mathrm{RH}$ within the chamber (bottom axis) and the RH within the nephelometer (upper axis).

in the in situ humidification in the chamber measurements: (1) in the chamber, particles would continue to grow by coagulation during the humidification process. To test this hypothesis, the coagulation rate of particles was calculated before the humidification by measuring the evolution of the particle's size. We observed an increase of $2 \%$ per hour that cannot explain the change in their size observed during humidification. Furthermore, we found no significant decrease of the number concentration due to the coagulation of particles. (2) The hygroscopic behaviour of polydisperse particles was investigated with respect to that of monodispersed particles as studied with the H-TDMA. Schuttlefield et al. (2007) indicated that taking into account polydispersed particle distributions would result in a continuous growth due to the fact that nanoparticles would deliquesce sooner than large ones. This is contradicted by Biskos et al. (2006), who did not observe any nanosize effect on the RH values of deliquescence. We agree with this conclusion, as we did not observe any modification of the shape of size distribution, suggesting that the particle hygroscopicity would be dependent on size, but only a displacement of the overall particle size distribution towards higher sizes. (3) The residence time for particles in the wet air stream was significantly longer when particles were humidified in situ in the chamber. It takes a few minutes in the chamber, instead of $15 \mathrm{~s}$ in the H-TDMA. Recently, Chan and Chan (2005) highlighted that hygroscopic measurements can be compromised if particles have not attained their equilibrium state in the measurements. Indeed, using attenuated total reflection Fourier transform infrared spectroscopy, Schuttlefield et al. (2007) observed that water was continuously absorbed on ammonium sulfate particles starting from as low as $3 \% \mathrm{RH}$. In their experiment, 

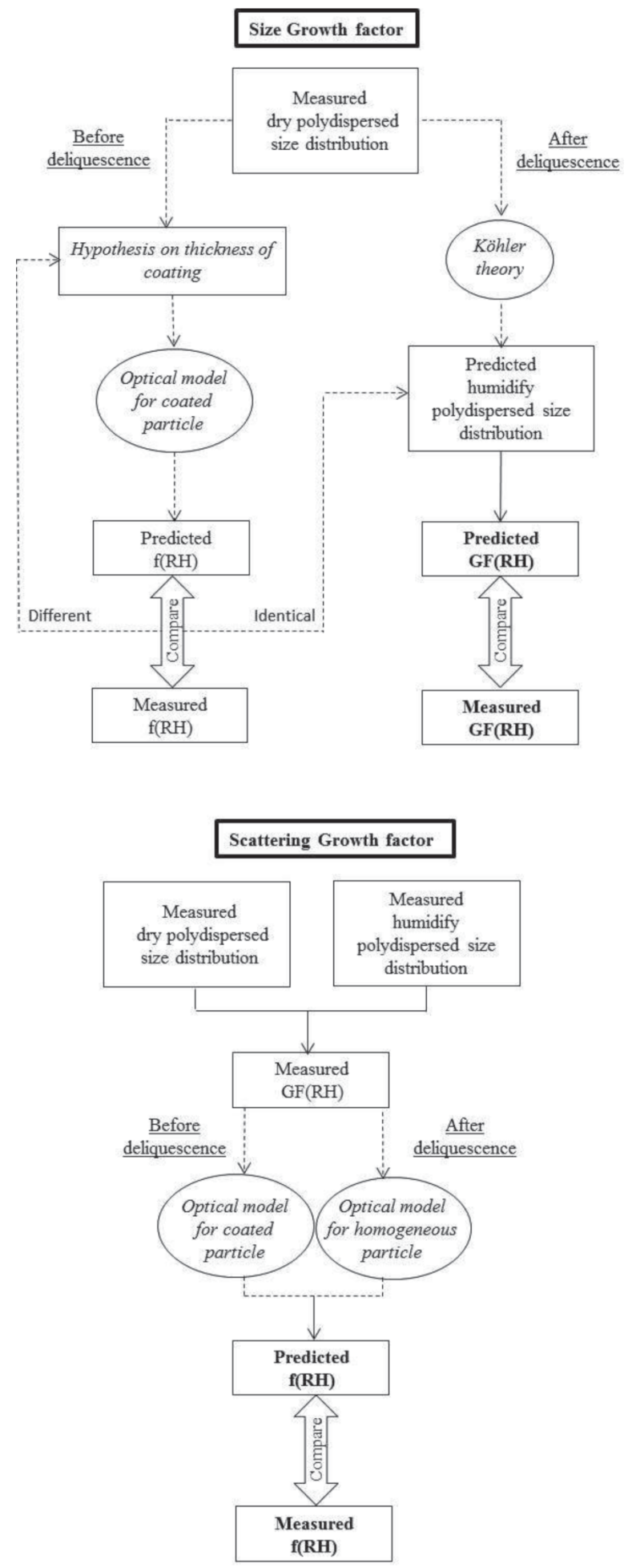

Fig. 10. Method used to compare measured and predicted size and scattering growth factor.

particles were allowed to equilibrate with water vapour for 20 min. Krueger et al. (2003) observed water uptake on $\mathrm{NaCl}$ particles prior to deliquescence with environmental scanning
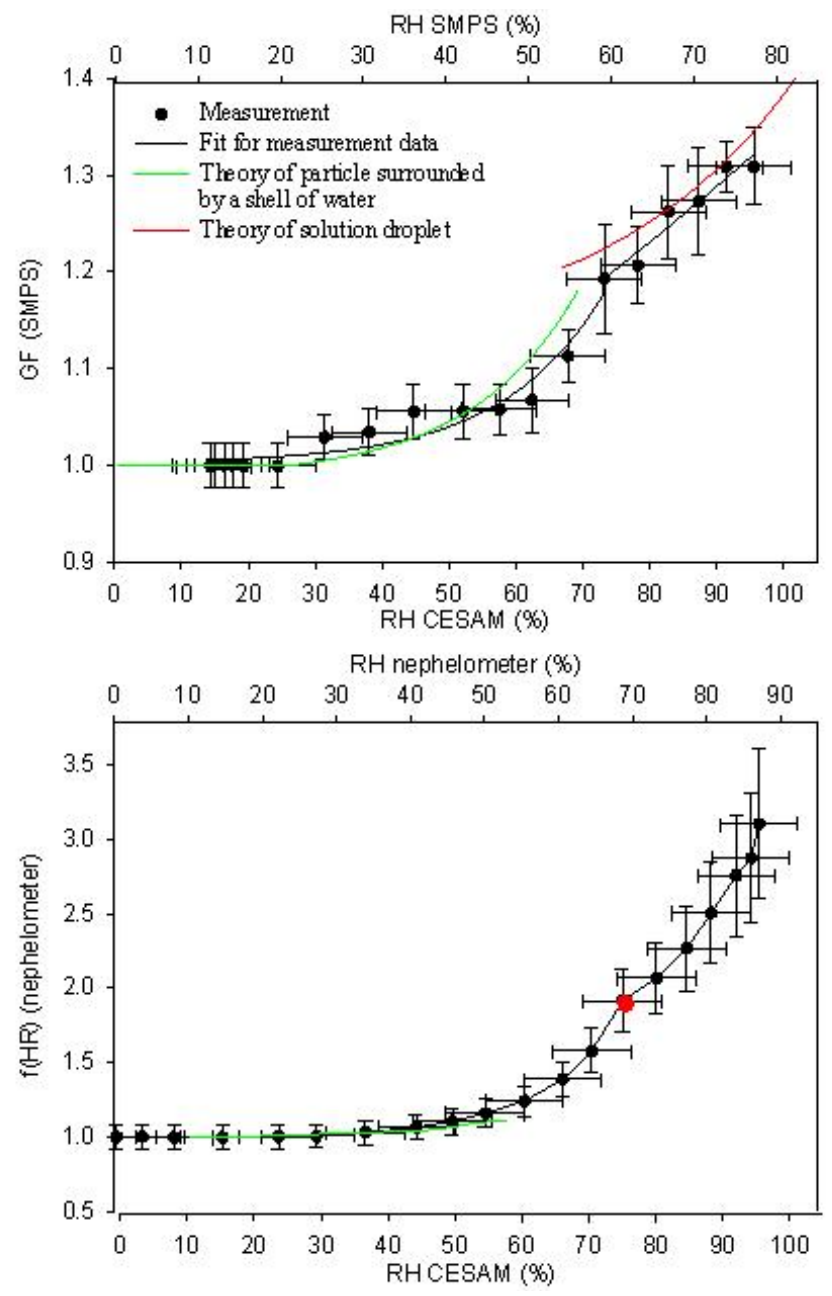

Fig. 11. Hygroscopic growth factor GF (a) and scattering growth factor $f(\mathrm{RH})$ (b) as a function of $\mathrm{RH}$ within the chamber (bottom axis) and the RH within the measuring instrument (upper axis) obtained for the experiment E1212. The measurements are shown in black circles. The modelled growth factors based on the theory describing ammonium sulfate particle surrounded by a shell of water (red line) and solution droplet (green line) is also added. The black line represents a fit through data measurement.

electron microscope. In particular, at $75 \% \mathrm{RH}$, these authors may find that over a $35 \mathrm{~min}$ period, particles become more spherical, although a solid $\mathrm{NaCl}$ core remained. Trainic et al. (2012) also showed that ammonium sulfate particles exposed to varying RH from $30 \%$ to $90 \% \mathrm{RH}$ during $1 \mathrm{~h}$, and then dried, exhibit a trend of increasing growth in size. The results indicate that care need to be taken of the equilibrium time for water uptake in investigating the aerosols hygroscopic properties. H-TDMA instruments induce limited residence time for humidification that might not be sufficient for complete water adsorption on ammonium sulfate particles. 


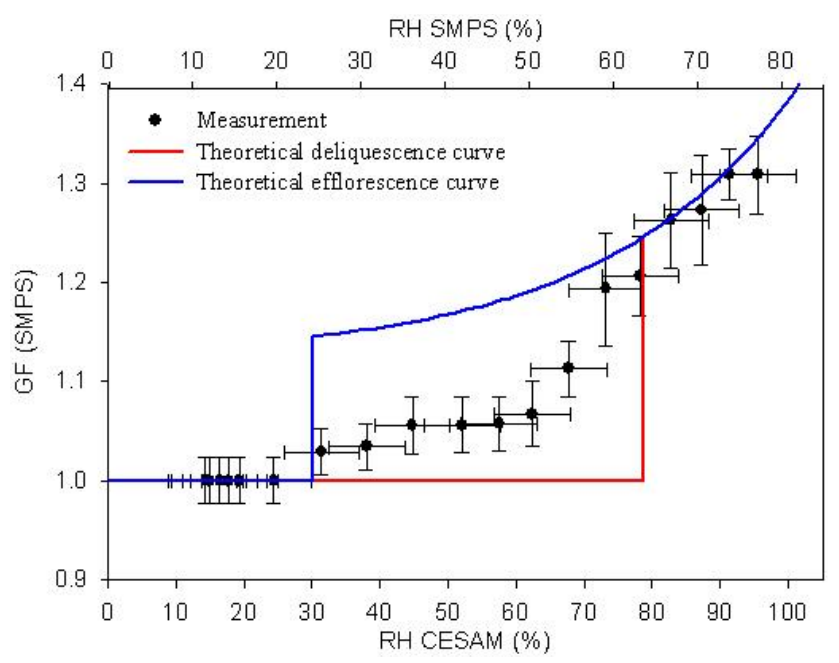

Fig. 12. Hygroscopic growth factor GF as a function of RH within the chamber (bottom axis) and the RH within the measuring instrument (upper axis) obtained for the experiment E1212. The measurements (black circles) are compared with the theoretical growth factors based on the Köhler theory for deliquescence (red line) and efflorescence (blue line). Theoretical curves take into account the Kelvin effect for particles smaller than $100 \mathrm{~nm}$.

\section{Atmospheric implications}

Our results suggest that the absorption of water by ammonium sulfate particles occurs well below the deliquescence point for RH ranging between 30 and $80 \%$, which is common in ambient atmospheric conditions. Humidification was performed during few minutes that may be of relevance of the aerosols transport in the atmosphere. As a consequence, depending on their RH history, ammonium sulfate particles may be surrounded by water layers or exist as an aqueous solution over a broad region for a wide range of $\mathrm{RH}$ values ranging from 30 to $80 \%$. The implications of this observation are important as water uptake below deliquescence will alter the scattering properties even on the deliquescence branch of the humidity growth curve, regardless of the fact that particles have undergone various cycles of evapo-condensation. This effect is not taken into account to date by most global models, which would consider that no growth occur before the deliquescence point (e.g., Martin et al., 2004; DeAndreis et al., 2012).

The implication for heterogeneous chemistry may also be significant. Knipping et al. (2000) have showed that the kinetics of many heterogeneous reactions depend on the phase of particles. As an example, dry ammonium sulfate particles have been found to be highly unreactive to $\mathrm{N}_{2} \mathrm{O}_{5}$, an important ozone precursor in the daytime (Mozurkewich and Calvert, 1988). However, significant reactivity of $\mathrm{N}_{2} \mathrm{O}_{5}$ with liquid ammonium sulfate particles was observed (Hu and Abbatt, 1997). Therefore, the wetting of ammonium sulfate particles below deliquescence may have important consequences in the gas-particle partitioning of organic compounds, contributing to the Secondary Organic Aerosols formation (SOA). This is consistent with finding by Kroll et al. (2005), who observed that the reactive uptake of glyoxal on aqueous seed contributes significantly to particle growth. Volkamer et al. (2009) also found SOA formation from glyoxal in the presence of ammonium sulfate particles at high RH.

\section{Conclusions}

We presented in this paper an optimized experimental set up to study, in situ and under controlled conditions close to those in the atmosphere, the hygroscopic behaviour of the size distribution and optical properties for polydispersed aerosols. This set up is based on the use of a high-volume atmospheric simulation chamber, CESAM, where water vapour and aerosols can be injected at various concentrations and kept at equilibrium for several minutes. The in situ relative humidity in the chamber can be varied from 0 to $100 \%$. In this paper we have presented the validation studies of the particle complex refractive index (CRI), representing the aerosol optical properties, and the size and scattering growth factors (GF and $f(\mathrm{RH})$, respectively) of the ammonium sulfate particles, which we used as a reference species of known optical and hygroscopic behaviour. Henceforth, our experimental results can be compared with literature values, as well as with theoretical calculations based on the Köhler and Mie theories for hygroscopicity and optical properties, respectively.

Values of CRI retrieved at dry conditions at one specific wavelength and also at an average in the visible spectrum are in good agreement with expected results from the literature. On the contrary, the comparison of our results on the aerosol hygroscopic behaviour depends on the experimental protocol. The expected hygroscopic behaviour of water uptake by ammonium sulfate aerosols on the growing branch on the humidification curve is obtained when measurements are performed on a narrow size class centred on $150 \mathrm{~nm}$ by our custom-built H-TDMA, in agreement with literature results. Conversely, polydisperse aerosols humidified for a longer time in the chamber display a different behaviour suggesting water uptake far below deliquescence for $\mathrm{RH}$ values as low as $30 \%$. Modelling of our experimental results can be achieved by assuming that, starting from $\mathrm{RH}=30 \%$, continuous absorption of water occurs in the form of a shell around the ammonium sulfate core particle. In the future, it will be interesting to generalize this kind of studies to other inorganic salt particles $\left(\mathrm{NaCl}, \mathrm{Na}_{2} \mathrm{SO}_{4}, \ldots\right)$ that exhibited prompt deliquescence in previous $\mathrm{H}$-TDMA experimental studies.

In conclusion, we consider that this pilot study is successful in illustrating the potential of the humidity-controlled CESAM simulation chamber in providing accurate data on the hygroscopic growth of both particle size and optical properties, and their mutual links. In particular, this protocol seems 
particularly adapted to the investigation of the optical and hygroscopic properties of secondary organic aerosols (SOA) from oxidation of volatile organic compounds (VOCs). As a matter of fact, SOA are generally thought to be hydrophilic species (Kanakidou et al., 2005) and it is possible that extended humidification times are required to achieve their equilibrium size due to strong kinetic effect (Chan and Chan, 2005). Our procedure seems valuable for measuring the optical properties at dry conditions for weakly absorbing aerosols. The possibility of applying this procedure also to the investigation of the absorptive properties of particles at humid conditions needs to be exploited.

\section{Supplementary material related to this article is available online at http://www.atmos-meas-tech.net/7/ 183/2014/amt-7-183-2014-supplement.pdf.}

Acknowledgements. This research work has been supported by the European Community within the seventh Framework Programme: Eurochamp-2 (EU-FP7 grant agreement no. 228335). The authors want to thank George Biskos and Barbounis Konstantinos (Univ. of Aegean) for their help in the development of the H-TDMA.

Edited by: P. Herckes

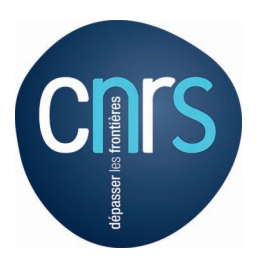

The publication of this article is financed by CNRS-INSU.

\section{References}

Albrecht, B. A.: Aerosols, cloud microphysics, and fractional cloudiness, Science, 245, 1227-1230, 1989.

Arnott, W. P., Hamasha, K., Moosmuller, H., Sheridan, P. J., and Ogren, J. A.: Towards aerosol light-absorption measurements with a 7-wavelength aethalometer: evaluation with a photoacoustic instrument and 3-wavelength nephelometer, Aerosol Sci. Tech., 39, 17-29, 2005.

Beaver, M. R., Garland, R. M., Hasenkopf, C. A., Baynard, T., Ravishankara, A. R., and Tolbert, M. A.: A laboratory investigation of the relative humidity dependence of light extinction by organic compounds from lignin combustion, Environ. Res. Lett., 3, 045003, doi:10.1088/1748-9326/3/4/045003, 2008.

Biskos, G., Paulsen, D., Russell, L. M., Buseck, P. R., and Martin, S. T.: Prompt deliquescence and efflorescence of aerosol nanoparticles, Atmos. Chem. Phys., 6, 4633-4642, doi:10.5194/acp-64633-2006, 2006.

Bodhaine, B. A.: Aerosol absorption measurements at Barrow, Mauna Loa and the south pole, J. Geophys. Res.-Atmos., 100, 8967-8975, doi:10.1029/95jd00513, 1995.
Bohren, C. F. and Huffman, D. R.: Absorption and Scattering of Light by Small Particles, Wiley, New York, 1983.

Bond, T. C. and Bergstrom, R. W.: Light absorption by carbonaceous particles: An investigative review, Aerosol Sci. Technol., 40, 27-67, doi:10.1080/02786820500421521, 2006.

Bond, T. C., Anderson, T. L., and Campbell, D.: Calibration and intercomparison of filter-based measurements of visible light absorption by aerosols, Aerosol Sci. Tech., 30, 582-600, doi:10.1080/027868299304435, 1999.

Cappa, C. D., Lack, D. A., Burkholder, J. B., and Ravishankara, A. R.: Bias in filter-based aerosol light absorption measurements due to organic aerosol loading: evidence from laboratory measurements, Aerosol Sci. Tech., 42, 1022-1032, 2008.

Chan, M. N. and Chan, C. K.: Mass transfer effects in hygroscopic measurements of aerosol particles, Atmos. Chem. Phys., 5, 2703-2712, doi:10.5194/acp-5-2703-2005, 2005.

Charlson, R. J., Schwartz, S. E., Hales, J. M., Cess, R. D., Coakley, J. A., Hansen, J. E., and Hofmann, D. J.: Climate forcing by anthropogenic aerosols, Science, 255, 423-430, 1992.

Collaud Coen, M., Weingartner, E., Apituley, A., Ceburnis, D., Fierz-Schmidhauser, R., Flentje, H., Henzing, J. S., Jennings, S. G., Moerman, M., Petzold, A., Schmid, O., and Baltensperger, U.: Minimizing light absorption measurement artifacts of the Aethalometer: evaluation of five correction algorithms, Atmos. Meas. Tech., 3, 457-474, doi:10.5194/amt-3-457-2010, 2010.

Covert, D. S., Charlson, R. J., and Ahlquist, N. C.: A study of the relationship of chemical composition and humidity to light scattering by aerosols, J. Appl. Meteorol., 11, 968-976, 1972.

Covert, D. S., Heintzenberg, J., and Hansson, H.-C.: "Electrooptical Detection of External Mixtures in Aerosols", Aerosol Sci. Tech, 12, 446-456, 1990.

Cruz, C. N. and Pandis, S. N.: Deliquescence and hygroscopic growth of mixed inorganic30 organic atmospheric aerosol, Environ. Sci. Technol., 34, 4313-4319, 2000.

Déandreis, C., Balkanski, Y., Dufresne, J. L., and Cozic, A.: Radiative forcing estimates of sulfate aerosol in coupled climatechemistry models with emphasis on the role of the temporal variability, Atmos. Chem. Phys., 12, 5583-5602, doi:10.5194/acp12-5583-2012, 2012.

Dinar, E., Riziq, A. A., Spindler, C., Erlick, C., Kiss, G., and Rudich, Y.: The complex refractive index of atmospheric and model humiclike substances (HULIS) retrieved by a cavity ring down aerosol spectrometer (CRD-AS), Faraday Discuss., 137, 279-295, 2008.

Dougle, P. G., Veefkind, J. P., and ten Brink, H. M.: Crystallisation of mixtures of ammonium nitrate, ammonium sulphate and soot, J. Aerosol Sci., 29, 375-386, 1998.

Duplissy, J., Gysel, M., Sjogren, S., Meyer, N., Good, N., Kammermann, L., Michaud, V., Weigel, R., Martins dos Santos, S., Gruening, C., Villani, P., Laj, P., Sellegri, K., Metzger, A., McFiggans, G. B., Wehrle, G., Richter, R., Dommen, J., Ristovski, Z., Baltensperger, U., and Weingartner, E.: Intercomparison study of six HTDMAs: results and recommendations, Atmos. Meas. Tech., 2, 363-378, doi:10.5194/amt-2-363-2009, 2009.

Flores, J. M., Trainic, M., Borrmann, S., and Rudich, Y.: Effective broadband refractive index retrieval by a white light optical particle counter, Phys. Chem. Chem. Phys., 11, 7943-7950, 2009.

Forster, P., Ramaswamy, V., Artaxo, P., Berntsen, T., Betts, R., Fahey, D. W., Haywood, J., Lean, J., Lowe, D. C., Myhre, G., 
Nganga, J., Prinn, R., Raga, G., Schulz, M., and Van Dorland, R.: Radiative Forcing of Climate Change, in: Climate Change 2007: The Physical Science Basis, Contribution of Working Group I to the Fourth Assessment Report of the Intergovernmental Panel on Climate Change, edited by: Solomon, S., Qin, D., Manning, M., Chen, Z., Marquis, M., Averyt, K. B., Tignor, M., and Miller, H. L., 2007.

Garland, R. M., Ravishankara, A. R., Lovejoy, E. R., Tolbert, M. A., and Baynard, T.: Parameterization for the relative humidity dependence of light extinction: organic-ammonium sulfate aerosol, J. Geophys. Res., 112, D19303, doi:10.1029/2006JD008179, 2007.

Gysel, M., Weingartner, E., and Baltensperger, U.: Hygroscopicity of aerosol particles at low temperatures, 2. theoretical and experimental hygroscopic properties of laboratory generated aerosols, Environ. Sci. Technol., 36, 63-68, 2001.

Hämeri, K., Väkevä, M., Hansson, H.-C., and Laaksonen, A.: Hygroscopic growth of ultrafine ammonium sulphate aerosol measured using an ultrafine tandem differential mobility analyzer, J. Geophys. Res., 105, 22231-22242, 2000.

Hand, J. L. and Kreidenweis, S. M.: A new method for retrieving particle refractive index and effective density from aerosol size distribution data, Aerosol Sci. Tech., 36, 1012-1026, 2002.

Hansen, J., Sato, M., and Ruedy, R.: Radiative forcing and climate response, J. Geophys. Res. Atmos., 102, 6831-6864, 1997.

Haywood, J. M. and Ramaswamy, V.: Global sensitivity studies of the direct radiative forcing due to anthropogenic sulfate and black carbon aerosols, J. Geophys. Res., 103, 6043-6058, 1998.

Haywood, J. M., Schwarzkopf, M. D., and Ramaswamy, V.: Estimates of radiative forcing due to modeled increases in tropospheric ozone, J. Geophys. Res., 103, 16999-17007, 1998.

Hegg, D., Larson, T., and Yuen, P. F.: A theoretical-study of the effect of relative-humidity on light scattering by tropospheric aerosols, J. Geophys. Res. Atmos., 98, 18435-18439, 1993.

Heim, M., Mullins, B. J., Umhauer, H., and Kasper, G.: Performance evaluation of three optical particle counters with an efficient multimodal calibration method, J. Aerosol Sci., 39, 10191031, 2008.

Henry, K. M. and Donahue, N. M.: Photochemical aging of alphapinene secondary organic aerosol: effects of oh radical sources and photolysis, J. Phys. Chem. A, 116, 5932-5940, 2012.

Hinds, W. C.: Aerosol Technology: Properties, Behaviour, and Measurement of Airborne Particles, Book, 1999.

$\mathrm{Hu}$, J. H. and Abbatt, J. P. D.: Reaction probabilities for $\mathrm{N}_{2} \mathrm{O}_{5}$ hydrolysis on sulfuric acid and ammonium sulfate aerosols at room temperature, J. Phys. Chem. A, 101, 871-878, 1997.

Huff Hartz, K. E., Rosenorn, T., Ferchak, S. R., Raymond, T. M., Bilde, M., Donahue, N. M., and Pandis, S. N.: Cloud condensation nuclei activation of monoterpene and sesquiterpene secondary organic aerosol, J. Geophys. Res., 110, D14208, doi:10.1029/2004JD005754, 2005.

Kanakidou, M., Seinfeld, J. H., Pandis, S. N., Barnes, I., Dentener, F. J., Facchini, M. C., Van Dingenen, R., Ervens, B., Nenes, A., Nielsen, C. J., Swietlicki, E., Putaud, J. P., Balkanski, Y., Fuzzi, S., Horth, J., Moortgat, G. K., Winterhalter, R., Myhre, C. E. L., Tsigaridis, K., Vignati, E., Stephanou, E. G., and Wilson, J.: Organic aerosol and global climate modelling: a review, Atmos. Chem. Phys., 5, 1053-1123, doi:10.5194/acp-5-1053-2005, 2005.
Knipping, E. M., Lakin, M. J., Foster, K. L., Jungwirth, P., Tobias, D. J., Gerber, R. B., Dabdub, D., and Finlayson-Pitts, B. J.: Experiments and simulations of ion-enhanced interfacial chemistry on aqueous $\mathrm{NaCl}$ aerosols, Science, 288, 301-306, 2000.

Kroll, J. H., Ng, N. L., Murphy, S. M., Varutbangkul, V., Flagan, R. C., and Seinfeld, J. H.: Chamber studies of secondary organic aerosol growth by reactive uptake of simple carbonyl,compounds, J. Geophys. Res.-Atmos., 110, D23207, doi:10.1029/2005JD006004, 2005.

Krueger, B. J., Grassian, V. H., Iedema, M. J., Cowin, J. P., and Laskin, A.: Probing heterogeneous chemistry of individual atmospheric particles using scanning electron microscopy and energydispersive X-Ray analysis, Anal. Chem., 75, 5170-5179, 2003.

Kus, P., Carrico, C., Rood, M., and Williams, A.: Measured and modeled light scattering values for dry and hydrated laboratory aerosols, J. Atmos. Ocean. Tech., 21, 981-994, 2004.

Liu, B. Y. H., Pui, D. Y. H., Whitby, K. T., and Kittelson, D. B.: The aerosol mobility chromatograph: a new detector for sulfuric acid aerosols, Atmos. Environ., 12, 99-104, 1978.

Liu, X., Cheng, Y., Zhang, Y., Jung, J., Sugimoto, N., Chang, S.Y., Kim, Y. J., Fan, S., and Zeng, L.: Influences of relative humidity and particle chemical composition on aerosol scattering properties during the 2006 PRD campaign, Atmos. Environ., 42, 1525-1536, 2008.

Lohmann, U. and Feichter, J.: Global indirect aerosol effects: a review, Atmos. Chem. Phys., 5, 715-737, doi:10.5194/acp-5-7152005, 2005.

Malm, W. C., Day, D. E., Kreidenweis, S. M., Collett, J., Jeffrey, L., Carrico, C., McMeeking, G., and Lee, T.: Hygroscopic properties of an organic-laden aerosol, Atmos. Environ., 39, 4969-4982, 2005.

Martin, S. T.: Phase transitions of aqueous atmospheric particles, Chem. Rev., 100, 3403-3453, 2000.

Martin, S. T., Hung, H.-M., Park, R. J., Jacob, D. J., Spurr, R. J. D., Chance, K. V., and Chin, M.: Effects of the physical state of tropospheric ammonium-sulfate-nitrate particles on global aerosol direct radiative forcing, Atmos. Chem. Phys., 4, 183 214, doi:10.5194/acp-4-183-2004, 2004.

Meyer, N. K., Duplissy, J., Gysel, M., Metzger, A., Dommen, J., Weingartner, E., Alfarra, M. R., Prevot, A. S. H., Fletcher, C., Good, N., McFiggans, G., Jonsson, A. M., Hallquist, M., Baltensperger, U., and Ristovski, Z. D.: Analysis of the hygroscopic and volatile properties of ammonium sulphate seeded and unseeded SOA particles, Atmos. Chem. Phys., 9, 721-732, doi:10.5194/acp-9-721-2009, 2009.

Mozurkewich, M. and Calvert, J. G.: Reaction probability of N2O5 on aqueous aerosols, J. Geophys. Res.-Atmos., 93, 1588915896, 1988.

Nakayama, T., Matsumi, Y., Sato, K., Imamura, T., Yamazaki, A., and Uchiyama, A.: Laboratory studies on optical properties of secondary organic aerosols generated during the photooxidation of toluene and the ozonolysis of alphapinene, J. Geophys. Res.Atmos., 115, D24204, doi:10.1029/2010JD014387, 2010.

Nemesure, S., Wagener, R., and Schwartz, S. E.: Direct shortwave forcing of climate by the anthropogenic sulfate aerosol: sensitivity to particle size, composition, and relative humidity, J. Geophys. Res.-Atmos., 100, 26105-26116, 1995.

Orr Jr., C., Hurd, F. K., and Corbett, W. J.: Aerosol size and relative humidity, J. Coll. Sci., 13, 472-482, 1958. 
Petters, M. D., Wex, H., Carrico, C. M., Hallbauer, E., Massling, A., McMeeking, G. R., Poulain, L., Wu, Z., Kreidenweis, S. M., and Stratmann, F.: Towards closing the gap between hygroscopic growth and activation for secondary organic aerosol - Part 2: Theoretical approaches, Atmos. Chem. Phys., 9, 3999-4009, doi:10.5194/acp-9-3999-2009, 2009.

Petzold, A., Kopp, C., and Niessner, R.: The dependence of the specific attenuation cross-section on black carbon mass fraction and particle size, Atmos. Environ., 31, 661-672, doi:10.1016/S13522310(96)00245-2, 1997.

Prenni, A. J., DeMott, P. J., and Kreidenweis, S. M.: Water uptake of internally mixed particles containing ammonium sulfate and dicarboxylic acids, Atmos. Environ., 37, 4243-4251, 2003.

Pruppacher, H. and Klett, J. D.: Microphysics of Clouds and Precipitation, Book, 1996.

Riziq, A. A., Trainic, M., Erlick, C., Segre, E., and Rudich, Y.: Extinction efficiencies of coated absorbing aerosols measured by cavity ring down aerosol spectrometry, Atmos. Chem. Phys. Discuss., 7, 18113-18144, doi:10.5194/acpd-7-18113-2007, 2007.

Saathoff, H., Naumann, K.-H., Schnaiter, M., Schöck, W., Mähler, O., Schurath, U., Weingartner, E., Gysel, M., and Baltensperger, $\mathrm{U}$.: Coating of soot and $\left(\mathrm{NH}_{4}\right)_{2} \mathrm{SO}_{4}$ particles by ozonolysis products of $\alpha$-pinene, J. Aerosol Sci., 34, 1297-1321, 2003.

Saxena, P., Hildemann, L. M., McMurry, P. H., and Seinfeld, J. H.: Organics alter hygroscopic behaviour of atmospheric particles, J. Geophys. Res., 100, 18755-18770, 1995.

Schuttlefield, J., Al-Hosney, H., Zachariah, A., and Grassian, V. H.: Attenuated total reflection fourier transform infrared spectroscopy to investigate water uptake and phase transitions in atmospherically relevant particles, Appl. Spectrosc., 61, 283-292, 2007.

Sjogren, S., Gysel, M., Weingartner, E., Baltensperger, U., Cubison, M. J., Coe, H., Zardini, A., Marcolli, C., Krieger, U. K., and Peter, T.: Hygroscopic growth and water uptake kinetics of twophase aerosol particles consisting of ammonium sulfate, adipic and humic acid mixtures, J. Aerosol Sci., 38, 157-171, 2007.

Sorooshian, A., Hersey, S., Brechtel, F. J., Corless, A., Flagan, R. C., and Seinfeld, J. H.: Rapid, Size-Resolved Aerosol Hygroscopic Growth Measurements: Differential Aerosol Sizing and Hygroscopicity Spectrometer Probe (DASH-SP), Aerosol Sci. Tech., 42, 445-464, 2008.

Svenningsson, I. B., Hansson, H. C., Wiedensohler, A., Ogren, J. A., Noone, K. J., and Hallberg, A.: Hygroscopic growth of aerosolparticles in the Po Valley, Tellus B, 44, 556-569, 1992.

Swietlicki, E. and Hansson, H.-C.: Hygroscopic properties of submicrometer atmospheric aerosol particles measured with $\mathrm{H}$ TDMA instruments in various environments - a review, Tellus B, 60, 432-469, 2008.

Tang, I. N.: Chemical and size effects of hygroscopic aerosols on light scattering coefficients, J. Geophys. Res., 101, 1924519250, 1996.

ten Brink, H. M., Khlystov, A., Kos, G. P. A., Tuch, T., Roth, C., and Kreyling, W.: A high-flow humidograph for testing the water uptake by ambient aerosol, Atmos. Environ., 34, 4291-4300, 2000 .
Toon, O. B., Pollack, J. B., and Khare, B. N.: The optical constants of several atmospheric aerosol species: ammonium sulfate, aluminum oxide, and sodium chloride, J. Geophys. Res., 81, 57335748, 1976.

Trainic, M., Riziq, A. A., Lavi, A., and Rudich, Y.: Role of interfacial water in the heterogeneous uptake of glyoxal by mixed glycine and ammonium sulfate aerosols, J. Phys. Chem. A, 116, 5948-5957, 2012.

Tritscher, T., Dommen, J., DeCarlo, P. F., Gysel, M., Barmet, P. B., Praplan, A. P., Weingartner, E., Prévôt, A. S. H., Riipinen, I., Donahue, N. M., and Baltensperger, U.: Volatility and hygroscopicity of aging secondary organic aerosol in a smog chamber, Atmos. Chem. Phys., 11, 11477-11496, doi:10.5194/acp-1111477-2011, 2011.

Varutbangkul, V., Brechtel, F. J., Bahreini, R., Ng, N. L., Keywood, M. D., Kroll, J. H., Flagan, R. C., Seinfeld, J. H., Lee, A., and Goldstein, A. H.: Hygroscopicity of secondary organic aerosols formed by oxidation of cycloalkenes, monoterpenes, sesquiterpenes, and related compounds, Atmos. Chem. Phys., 6, 23672388, doi:10.5194/acp-6-2367-2006, 2006.

Volkamer, R., Ziemann, P. J., and Molina, M. J.: Secondary Organic Aerosol Formation from Acetylene $\left(\mathrm{C}_{2} \mathrm{H}_{2}\right)$ : seed effect on SOA yields due to organic photochemistry in the aerosol aqueous phase, Atmos. Chem. Phys., 9, 1907-1928, doi:10.5194/acp9-1907-2009, 2009.

Wang, J., Doussin, J. F., Perrier, S., Perraudin, E., Katrib, Y., Pangui, E., and Picquet-Varrault, B.: Design of a new multi-phase experimental simulation chamber for atmospheric photosmog, aerosol and cloud chemistry research, Atmos. Meas. Tech., 4, 2465-2494, doi:10.5194/amt-4-2465-2011, 2011.

Weingartner, E., Saathoff, H., Schnaiter, M., Streit, N., Bitnar, B., and Baltensperger, U.: Absorption of light by soot particles: determination of the absorption coefficient by means of aethalometers, J. Aerosol Sci., 34, 1445-1463, 2003.

Wex, H., Kiselev, A., Stratmann, F., Zoboki, J., and Brechtel, F.: Measured and modeled equilibrium sizes of $\mathrm{NaCl}$ and $\left(\mathrm{NH}_{4}\right)_{2} \mathrm{SO}_{4}$ particles at relative humidities up to $99.1 \%$, J. Geophys. Res., 110, 955-989, 2005.

Wex, H., Petters, M. D., Carrico, C. M., Hallbauer, E., Massling, A., McMeeking, G. R., Poulain, L., Wu, Z., Kreidenweis, S. M., and Stratmann, F.: Towards closing the gap between hygroscopic growth and activation for secondary organic aerosol: Part 1 - Evidence from measurements, Atmos. Chem. Phys., 9, 3987-3997, doi:10.5194/acp-9-3987-2009, 2009.

Yasmeen, F., Vermeylen, R., Maurin, N., Perraudin, E., Doussin, J. F., and Claeys, M.: Characterisation of tracers for aging of alpha-pinene secondary organic aerosol using liquid chromatography/negative ion electrospray ionisation mass spectrometry, Environ. Chem., 9, 236-246, doi:10.1071/en11148, 2012.

Yoon, S.-C. and Kim, J.: Influences of relative humidity on aerosol optical properties and aerosol radiative forcing during ACE-Asia, Atmos. Environ., 40, 4328-4338, 2006. 